\title{
Neural reflex regulation of arterial pressure in pathophysiological conditions: interplay among the baroreflex, the cardiopulmonary reflexes and the chemoreflex
}

E.C. Vasquez, S.S. Meyrelles, H. Mauad and A.M. Cabral
Departamento de Ciências Fisiológicas, Centro Biomédico, Universidade Federal do Espírito Santo, 29040-091 Vitória, ES, Brasil

\section{Correspondence \\ E.C. Vasquez \\ Departamento de Ciências \\ Fisiológicas \\ CBM, UFES \\ Av. Marechal Campos, 1468 \\ 29040-091 Vitória, ES \\ Brasil \\ Fax: 55 (027) 335-7330}

Presented at the International Symposium "Neuroendocrine Control of Body Fluid Homeostasis", Ribeirão Preto, SP, Brasil, August 17-20, 1996.

Received August 26, 1996 Accepted November 29, 1996

\begin{abstract}
The maintenance of arterial pressure at levels adequate to perfuse the tissues is a basic requirement for the constancy of the internal environment and survival. The objective of the present review was to provide information about the basic reflex mechanisms that are responsible for the moment-to-moment regulation of the cardiovascular system. We demonstrate that this control is largely provided by the action of arterial and non-arterial reflexes that detect and correct changes in arterial pressure (baroreflex), blood volume or chemical composition (mechanoand chemosensitive cardiopulmonary reflexes), and changes in bloodgas composition (chemoreceptor reflex). The importance of the integration of these cardiovascular reflexes is well understood and it is clear that processing mainly occurs in the nucleus tractus solitarii, although the mechanism is poorly understood. There are several indications that the interactions of baroreflex, chemoreflex and Bezold-Jarisch reflex inputs, and the central nervous system control the activity of autonomic preganglionic neurons through parallel afferent and efferent pathways to achieve cardiovascular homeostasis. It is surprising that so little appears in the literature about the integration of these neural reflexes in cardiovascular function. Thus, our purpose was to review the interplay between peripheral neural reflex mechanisms of arterial blood pressure and blood volume regulation in physiological and pathophysiological states. Special emphasis is placed on the experimental model of arterial hypertension induced by N-nitro-L-arginine methyl ester (L-NAME) in which the interplay of these three reflexes is demonstrable.
\end{abstract}

\section{Introduction}

The maintenance of arterial pressure and blood volume at levels adequate to perfuse the tissues is a basic requirement for the constancy of the internal environment and survival. The minute-to-minute control of cardiovascular function is achieved through arterial and non-arterial reflexes that detect
Key words

- Arterial pressure

- Bezold-Jarisch reflex

- Baroreflex

- Chemoreflex and correct changes in arterial blood pressure (baroreceptor reflex), blood volume or chemical composition (cardiopulmonary reflexes), and specifically changes in oxygen, dioxide tension and $\mathrm{pH}$ (chemoreceptor reflex) (1-6). It is surprising that so little appears in the literature about the integration of these neural reflexes in cardiovascular function. Thus, our purpose was to review the 
interplay between peripheral neural reflex mechanisms of arterial blood pressure and blood volume regulation in physiological and pathophysiological states.

This review provides evidence concerning the importance of the major role of the autonomic nervous system in arterial hypertension and other cardiovascular disorders. Our purpose is not to provide a comprehensive review of arterial blood pressure regulation but to concentrate on the areas in which new ideas have developed lately. Thus, special emphasis is placed on experimental arterial hypertension induced by inhibition of nitric oxide synthase (N-nitro-L-arginine methyl ester (L-NAME)-induced hypertension) which is characterized by an enhancement of the baroreceptor, chemoreceptor and Bezold-Jarisch reflexes, mainly due to the hyperresponsiveness of the pacemaker muscarinic receptors (7-9). In other models of experimental hypertension and in experimental myocardial infarction these reflexes are also altered, but not in the same direction. There is evidence that the left ventricular hypertrophy following these pathophysiological states can contribute to the derangement of these reflexes.

\section{Arterial baroreceptor reflex}

The maintenance of arterial blood pressure at adequate levels to perfuse the tissues during different conditions is a basic requirement for the survival of mammals and is achieved by many complex neurohumoral mechanisms. The main purpose of the baroreflex function is to provide rapid and efficient stabilization of arterial blood pressure on a beat-to-beat basis by means of strategically located arterial sensors which are sensitive to high blood pressure and are known as arterial baroreceptors. The receptor endings of this neural system terminate primarily in the adventitia of the carotid sinus and aortic arch with their soma located in the petrosal and nodose ganglia, respec- tively. At each arterial systole, the stretching of these sensors depolarizes them and action potentials are then triggered and travel centrally to synapse onto neurons in the nucleus tractus solitarii (NTS) in the dorsal medulla. These second-order neurons project to the caudal ventrolateral medulla (CVLM) where they synapse with inhibitory neurons that in turn project to the rostral ventrolateral medulla (RVLM) and synapse with bulbospinal sympathoexcitatory neurons located in that area. In parallel, the second-order neurons maintain a tonic excitatory influence upon preganglionic parasympathetic neurons located in the dorsal nucleus of the vagus, rostral ventromedial medulla (RVMM) and mainly in the nucleus ambiguus. Thus, arterial baroreceptors maintain a moment-tomoment control of both sympathetic and vagal innervation to the cardiovascular system (for detailed reviews, see 1,2,10-12). The modulation of this system is not restricted to the medullary areas of neurons but is also influenced by supramedullary areas (1). Recently, our laboratory showed that lesion of the dorsal portion of the periaqueductal gray matter significantly decreases the basal arterial pressure and attenuates the baroreceptor control of heart rate in spontaneously hypertensive rats (13), indicating a functional role of this area in tonic and reflex maintenance of cardiovascular function under resting conditions.

Baroreceptor nerve activity is modulated by various neurohumoral factors such as the activity of ion channels and paracrine factors, in addition to changes in vascular structure and distensibility during physiological and pathological states $(14,15)$. Examples of factors modulating baroreceptor activity are a) the study supervised by Chapleau (16) demonstrating that endogenous nitric oxide and the nitric oxide donor, S-nitrosocysteine, suppress baroreceptor activity (Figure 1) and b) the study of Ferrari et al. (17) showing that the atrial natriuretic factor potentiates the baroreflex function in conscious rats. 

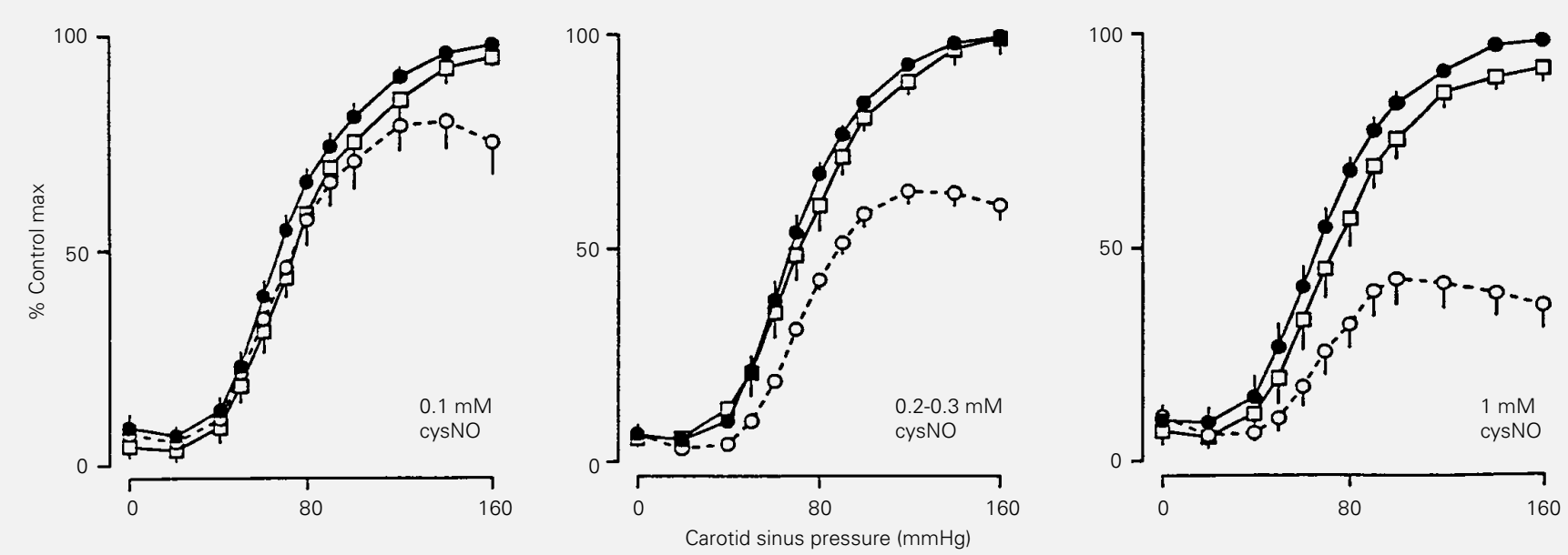

Figure 1 - Effect of S-nitrosocysteine (cysNO) on the baroreceptor activity in rabbits. Data are reported as means \pm SEM for $13-15$ measurements. Control; O, cysNO; $\square$, recovery. Reproduced from Ref. 16, with permission.

Although arterial baroreceptors are capable of acute and chronic resetting to high levels of arterial pressure (18), baroreflex dysfunction has been reported in arterial hypertension and other cardiovascular diseases both in clinical and experimental hypertension (19-21). There are data in the literature showing that the impairment of baroreflex sensitivity can be both a consequence or a cause of arterial hypertension. Changes in vascular structure and distensibility can occur in the aortic arch and sinoaortic vessel walls, for example with aging, arteriosclerosis and diabetes, which decrease baroreceptor activity and consequently can contribute to the development of arterial hypertension $(14,18)$. There is evidence that human hypertension may be induced or aggravated by impaired baroreceptor reflex control (4) as also observed in experimental models of genetic hypertension showing a decreased baroreceptor sensitivity in the prehypertensive stage of Dahlsalt rats and spontaneously hypertensive rats $(22,23)$. On the other hand, there is strong evidence that baroreceptor reflex impairment could be a consequence, rather than a cause, of hypertension both in human and experimental animals (21). Interestingly, impaired baroreflex control of heart rate is seen in renovascular $1 \mathrm{~K} 1 \mathrm{C}$ (1 day post-artery clipping) but not in $2 \mathrm{~K} 1 \mathrm{C}$ rats (3 days postartery clipping), both groups presenting the same levels of arterial hypertension $(24,25)$. This phenomenon suggests that differences in time course of baroreceptor hyporesponsiveness should be considered for each model of hypertension (Figure 2, right panels).

The baroreceptor dysfunction occurring in renovascular hypertension $(24,25)$ and in spontaneously hypertensive rats (26) is mainly due to a vagal deficit. However, with increasing hypertension the sympathetic component of the baroreflex is also impaired. Head and collaborators $(19,27)$ have studied the relationship between cardiovascular hypertrophy and baroreflex function extensively and have shown that cardiac hypertrophy may contribute to the vagal heart rate deficit.

In addition, our laboratory has also demonstrated in rats that the baroreflex control of heart rate can be exaggerated instead of attenuated in certain pathological conditions, such as hypertension induced by inhibition of nitric oxide synthase using L-NAME for 6 days (9; Figure 2, middle panels). In a recent study similar results were also observed in rabbits (28). In contrast, using a small dose of L-NAME for 35 days which causes less increase in arterial pressure a decrease of 

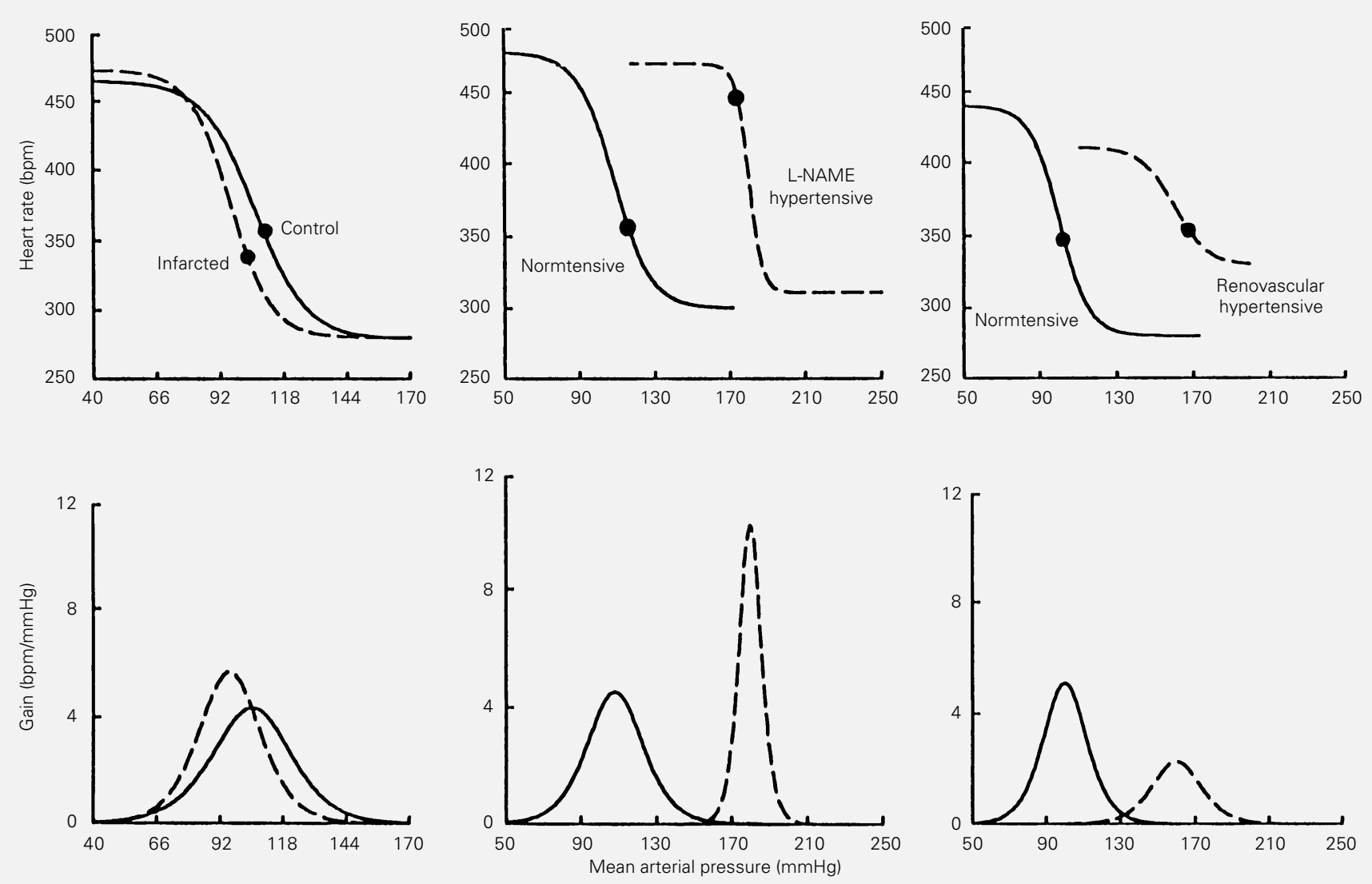

Figure 2 - Sigmoidal-fitting baroreceptor curve analysis (upper panels) comparing three pathophysiological conditions: myocardial infarction (left), LNAME-induced hypertension (middle) and one-kidney one clip renovascular hypertension (right) in conscious rats. Maximum baroreflex gains calculated from the first derivative of the logistic function are shown in the bottom panels. Data from Refs. 30 (left panels), 9 (middle panels) and 24 (right panels), with permission.

baroreflex sensitivity has been observed (29). The studies cited above suggest that the effects of L-NAME on baroreflex function are dependent on the time course of treatment and the dose used to inhibit nitric oxide synthase. Changes in baroreflex sensitivity can also occur in nonhypertensive conditions such as those studied by Meyrelles et al. (30) who showed enhanced sensitivity of the baroreflex control of heart rate in chronic myocardial infarction, which is accompanied by arterial hypotension and bradycardia (Figure 2, left panels).

\section{Cardiopulmonary reflexes}

Despite the importance of the arterial baroreceptors in the rapid stabilization of arterial pressure, studies performed in human beings and experimental animals during the last three decades have shown that neural reflex control of circulation depends not only on baroreflex but also, and to an important extent, on cardiopulmonary reflexes (21).

Vagal afferent pathways originating in cardiopulmonary receptors have been recognized for many years (6). The impulses arising in these receptors exert a tonic restraint on cardiac function and contribute to the physiological control of circulation. Cardiopulmonary reflexes are stimulated not only by changes in cardiac filling pressure but also by chemical agents $(31,32)$. In a recent report Ustinova and Schultz (33) showed that approximately $65 \%$ of cardiac 
vagal afferents in rats are sensitive to capsaicin and are mainly located in the left ventricle and atrium. This chemosensitive reflex is often referred to as the Bezold-Jarisch reflex which is characterized by simultaneous vagal-induced bradycardia and hypotension, the latter due to both sympathetic withdrawal and decreased cardiac output. Endogenously occurring substances stimulating the Bezold-Jarisch reflex are prostaglandins and serotonin through $5-\mathrm{HT}_{3}$ receptors.

The vagal afferents of the Bezold-Jarisch reflex project onto neurons located in the NTS $(5,6,34)$. The pre-ganglionic vagal neurons to the heart originate in the RVMM and mainly in the nucleus ambiguus $(35,36)$. The neurons controlling the efferent sympathetic activity to the resistance vessels and heart originate primarily in the $\operatorname{RVLM}(12,37,38)$. There is also evidence that the activation of central nervous muscarinic receptors (39) and 5- $\mathrm{HT}_{1 \mathrm{~A}}$ receptors (40) might be involved in the mediation of the Bezold-Jarisch reflex in rats.

Clinical and experimental data have shown that the Bezold-Jarisch reflex plays an important role in the control of cardiovascular function in normal and pathophysiological conditions (41-43). An indication of the functional role of this reflex in cardiovascular regulation was reported by Chianca Jr. and Machado (44), demonstrating an increased sensitivity of the Bezold-Jarisch reflex in both acute and chronic sinoaortic denervated rats (Figure 3 ).

In human beings the cardiopulmonary reflex has been reported to be exaggerated in borderline hypertension, normal in mild hypertension and impaired in hypertension accompanied by cardiac hypertrophy $(21,45)$. Results reported by Meyrelles et al. (42) demonstrating in conscious rats an impairment of the Bezold-Jarisch reflex in isoproterenol-induced cardiac hypertrophy agree with the hypothesis that myocardial hypertrophy is an important factor that accounts

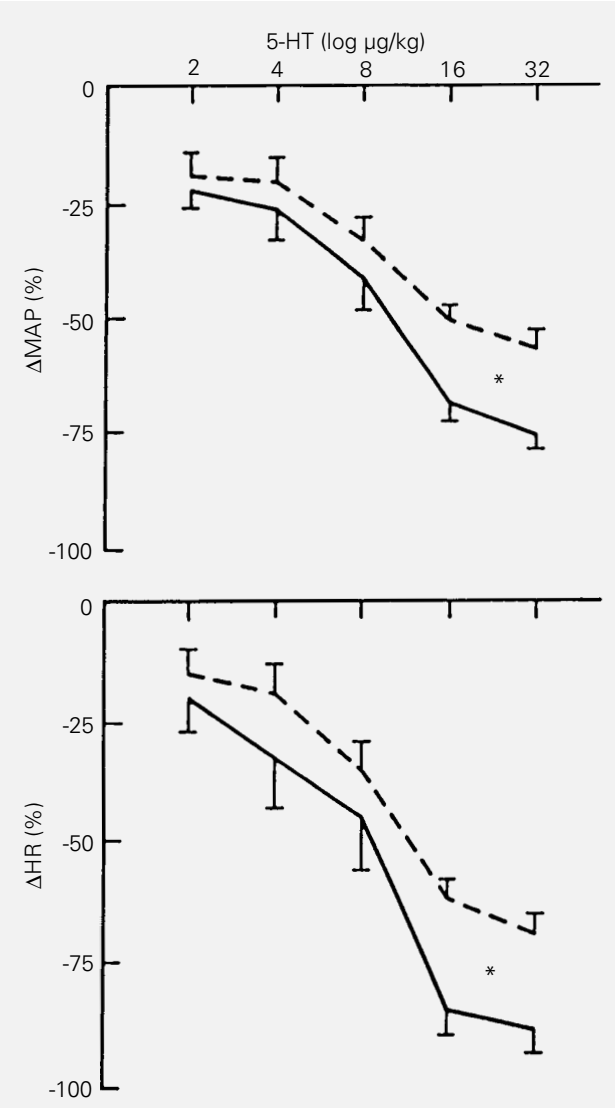

Figure 3 - Sensitivity of the Bezold-Jarisch reflex 15 days after sinoaortic deafferentation (solid line) compared to shamoperated rats (dashed line). Data reported as means \pm SEM for 8 rats in each group and indicate changes in heart rate (HR) and mean arterial pressure (MAP) in response to intravenous 5-hydroxytryptamine (5HT). ${ }^{*} \mathrm{P}<0.05$ compared to the control group for the doses of 16 and $32 \mu \mathrm{g} / \mathrm{kg}$ (ANOVA). Reproduced from Ref. 44, with permission. for the attenuation of this reflex in arterial hypertension. Recently, we also observed a decrease in the sensitivity of this reflex in myocardial infarcted rats, as illustrated in Figure 4, which could be due to a) the marked hypertrophy of the left atrium and/or to a non-infarcted hypertrophied left ventricle or b) to morphological necrotic injury of the innervation in the left ventricle which are the main origins of the vagal chemosensitive afferents (46).

The Bezold-Jarisch reflex has been tested in different models of experimental hypertension but the results are not comparable. This reflex is impaired in spontaneously hypertensive rats (47), renal hypertensive rats (48) and Dahl salt-hypertensive rats fed a low-salt diet (49). In contrast, a high-salt diet sensitizes the cardiopulmonary reflex in Dahl salt-resistant rats (50) and, as seen in Figure 5 , this reflex is also extremely enhanced in the arterial hypertension induced by inhibi- 

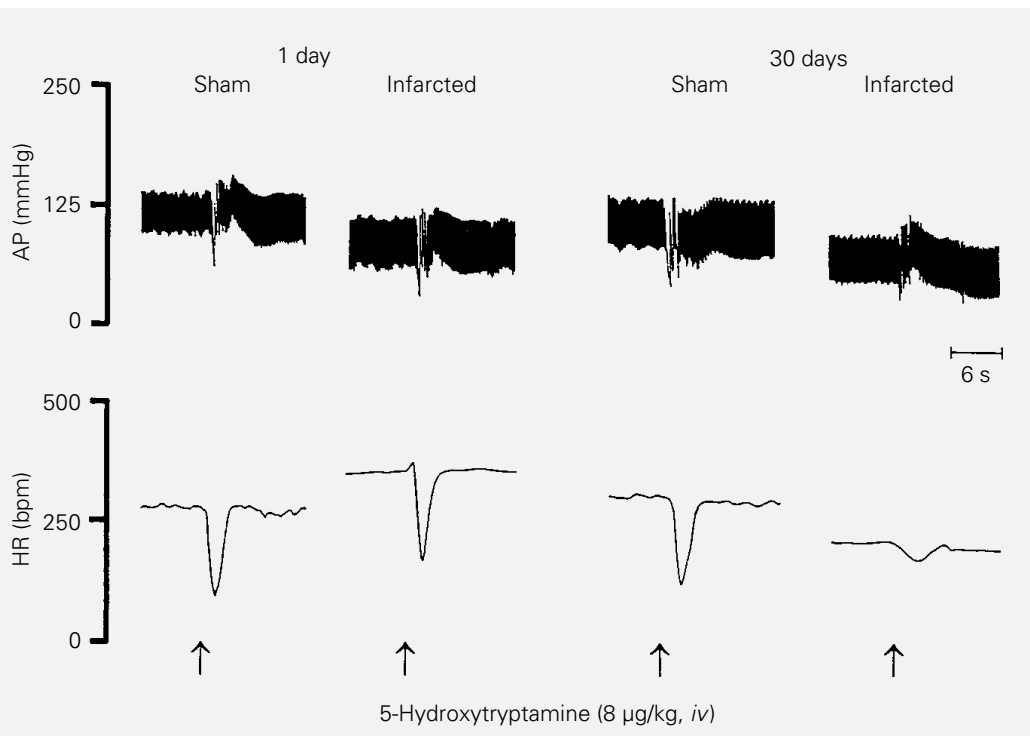

Figure 4 - Typical recording showing the changes in arterial pressure (AP) and heart rate (HR) in response to 5-hydroxytryptamine in an acute (1 day) and a chronic (30 days) myocardial infarcted rat (infarcted) compared with a sham-operated (sham) rat.
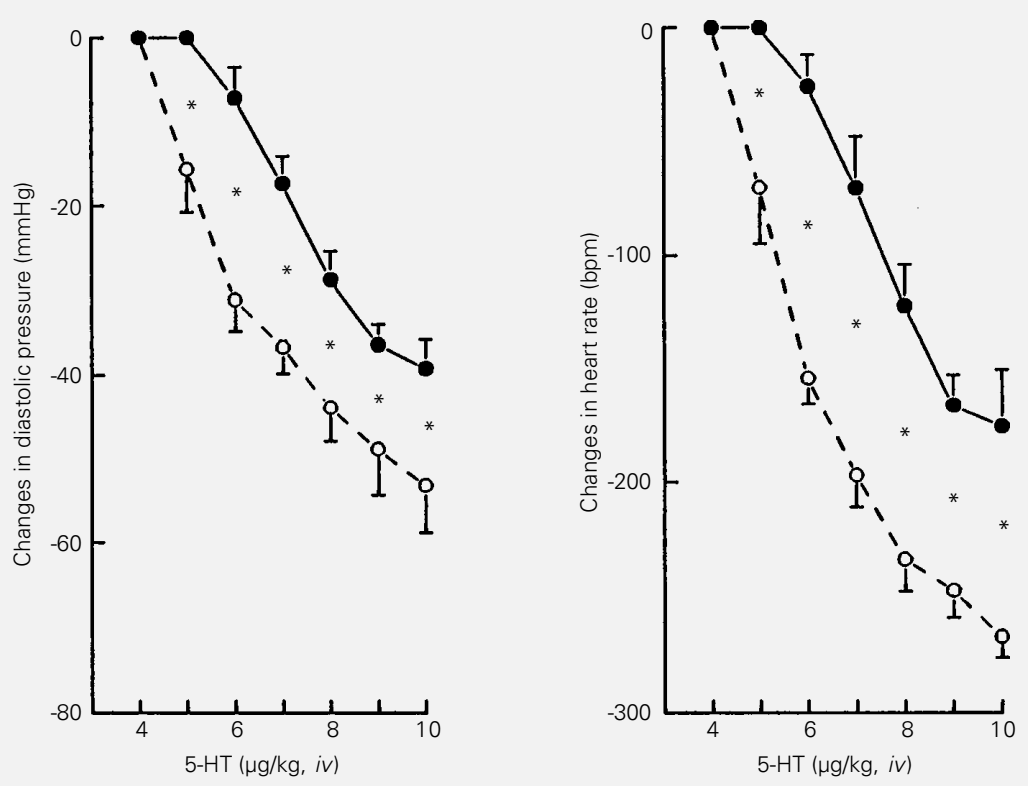

Figure 5 - 5-Hydroxytryptamine (5-HT)-induced Bezold-Jarisch reflex in hypertension caused by the inhibitor of nitric oxide synthase $\mathrm{N}$-nitro-L-arginine methyl ester (L-NAME, $0.5 \mathrm{mg} / \mathrm{ml}$ added to the drinking water for 6 days). Open circles: L-NAME-treated rats $(N=9)$; filled circles: control rats $(N=9)$. ${ }^{*} P<0.05$ compared to the control group (ANOVA). Reproduced from Ref. 51, with permission. tion of nitric oxide synthase using L-NAME (51).

\section{Chemoreceptor reflex}

The chemoreflex has been extensively studied as one of the neural components of arterial pressure regulation (52-60). The literature has shown a lot of evidence that the peripheral chemoreflex does not contribute solely to the ventilation control, but also to the neural mechanisms involved in arterial pressure control $(5,34,61)$.

Peripheral chemoreceptors are located in the aortic and carotid bodies and play a major role in all mammals, but the aortic bodies are functionally absent in the rabbit, mouse and rat $(3,62)$. The chemosensitive cells in the carotid bodies receive constant blood flow through a thin artery originated in the middle of the bifurcation of the common carotid artery (Figure 6) that maintains these cells in close contact with blood gases. When decreases in $\mathrm{pO}_{2}$ or increases in the $\mathrm{pCO}_{2}$ or $\mathrm{pH}$ occur these cells are excited and release a neurotransmitter that will stimulate the terminal innervation of the carotid sinus nerve (63). The afferent fibers from the carotid chemoreceptors join fibers from the baroreceptors to form the carotid sinus nerve, a branch of the glossopharyngeal nerve (64). Although the chemoreceptor and baroreceptor afferent fibers run together in the same nerve, i.e., the carotid sinus nerve, these afferents perform synapses at substantially separable sites in the NTS which has been identified as the primary central site that receives the afferents of several reflexes, including baro-, chemo- and cardiopulmonary ones $(34,53,65-67)$.

Some authors suggest that the commissural subnucleus of the NTS is the principal site of carotid chemoreceptor synapses $(56,58,68)$, placing them close to but not upon respiratory premotor neurons of the same nucleus (68). However, others suggest that the intermediolateral subnucleus of the 
NTS also plays an important role in the neurotransmission of this reflex $(53,69)$. The synapses of this reflex in the NTS promote the excitation of several neural pathways to different regions of the brainstem, producing changes in the sympathetic and vagal outflow to the heart and blood vessels and phrenic outflow to the lungs. In a study of the central neural pathways involved in the baroand chemoreflexes, Koshiya et al. (55) demonstrated that the CVLM contains an essential relay of the sympathetic baroreflex but the same area plays no important role in the sympathetic chemoreflex. These authors suggest that the chemoreflex and baroreflex may have a largely independent course through the medulla and that integration of their information used for sympathetic vasomotor control may occur as late as during the premotor neural stage in the RVLM.

Changes in chemoreceptor activity, especially in severe hypoxia, cause primary reflex effects on the cardiovascular system and evoke adjustments in the central drive for ventilation and cardiovascular function as an attempt to maintain adequate perfusion of vital organs $(68,70)$. The excitation of the chemoreceptors produces increased minute ventilation, systemic vasoconstriction, hypertension and bradycardia. Tachycardia is then usually observed as the steady-state response to arterial chemoreceptor activation, because the increase in ventilation inhibits vagal outflow to the heart (3).

Intravenous injection of potassium cyanide $(\mathrm{KCN})$ has been used to demonstrate the typical activation of the chemoreflex in rats $(63,69,71,72)$. KCN produces characteristic cardiovascular (bradycardia and hypertension), respiratory (tachypnea) and behavioral (alerting) responses which may be attributed to the actions of the chemical on chemosensitive cells. Selective aortic but not sino-aortic deafferentation does not prevent the chemoreflex $(71,73)$. In addition, the same investigators showed that these responses are not due to the sinus barorecep-

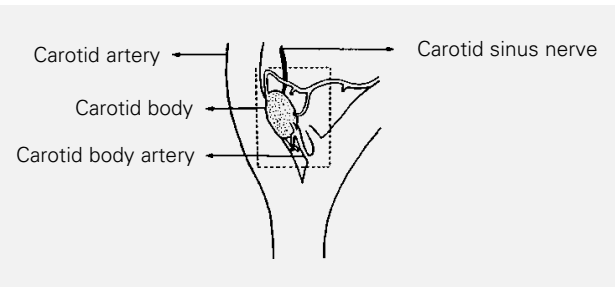

Figure 6 - Diagram illustrating the localization of the carotid body and the carotid arteries supplying the chemoreceptor cells of the rat. Reproduced from Ref. 71, with permission.

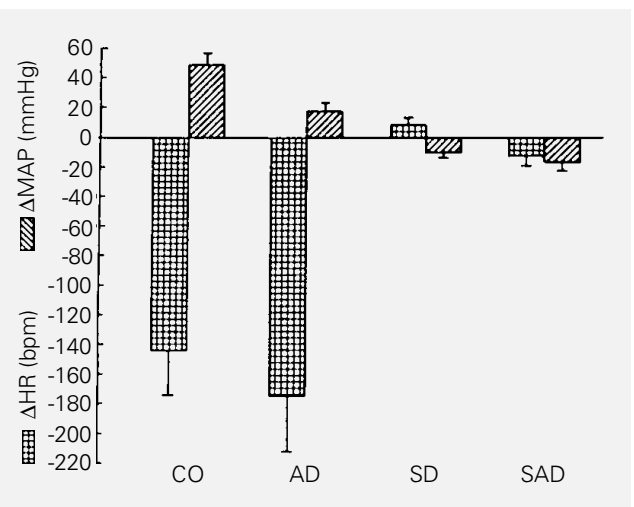

Figure 7 - Reflex arterial pressure and heart rate responses to intravenous injection of $\mathrm{KCN}$ (80 $\mu \mathrm{g} / \mathrm{rat}$ ) one day after sham (CO), aortic (AD), carotid sinus (SD) and sinoaortic (SAD) denervation. Reproduced from Ref 73 , with permission tor stimulation because the isolated elimination of chemoreceptors by carotid body artery ligation, preserving the carotid baroreceptor, completely abolished the responses evoked by intravenous KCN (Figure 7).

Morphological and biochemical changes in the carotid bodies $(74,75)$ such as increase in the size $(76,77)$ and changes in the capillaries (77) which could produce local ischemia (78) have been observed in several species of animals with arterial hypertension. Others have shown a close correlation between left ventricular hypertrophy and the size of carotid bodies (79). In addition, it has been observed that the hypoxia-induced chemoreflex is increased in spontaneously hypertensive rats (80). Increased chemoreceptor sensitivity was also observed in hypertensive humans (81).

\section{Interplay among baroreflex, chemore- flex and Bezold-Jarisch reflex}

The maintenance of arterial blood pressure at adequate levels and the integrity of body fluid composition and extracellular fluid 
volume in mammals depend on a series of interactions among sensing mechanisms capable of recognizing changes in parameters related to cardiovascular function. The studies summarized above indicate that, although individual classes of afferents have distinctive patterns of projection to the central medullary areas, the various subnuclei receive input from several different classes of afferents mediating different reflex responses (5). One aspect that is not completely understood is the interaction of the afferent signals in the NTS when different cardiovascular reflexes are excited simultaneously and how the efferent pathways act to achieve control of the circulation in humans and experimental animals $(1,58,66,69)$. Experiments in rabbits have shown that the presence of tonic cardiovascular inhibition exerted by the arterial baroreceptors tends to reduce the Bezold-Jarisch reflex, but the baroreceptors do not function adequately if there is a buffering of the cardiovascular inhibition produced by the cardiogenic reflex (82). Another example is the work of Daly (83) showing that inputs specifically related to lung inflation modified both the cardiac and the vascular responses to the baroreceptor and chemoreceptor reflex, independent of central respiratory activity.

Activation of the baroreflex or BezoldJarisch reflex and of the chemoreflex results in decreasing and increasing arterial pressure, respectively, but all produce bradycardia. However, many authors, including Spyer (5), have raised some questions: a) Are there individual neurons acting to integrate these afferent inputs related to baroreflex, BezoldJarisch reflex and chemoreflex? b) Do afferent fibers interact presynaptically? c) Is there a developed interneuronal system within the NTS that controls transmission through the various reflex pathways initiated there? d) Does this possible integration occur only in the central nervous system or also peripherally? Brunner et al. (84) showed in dogs that chemoreflex responses are strongly influ- enced by simultaneous activation of the baroreceptor reflex. On the other hand, it was also demonstrated in rats that activation of arterial baroreceptors attenuated excitatory chemoreceptor input to a subpopulation of NTS neurons (85), which is further evidence that reflex inputs interact to develop appropriate responses. Based on the literature, such interaction processes may involve other central areas that compose the chemoreflex, baroreflex and the Bezold-Jarisch reflex pathways such as a portion of the nucleus ambiguus, the reticular formation, the hypothalamic defense area, the periaqueductal gray matter, and the RVLM and RVMM $(55,57,70,86)$. Additional studies are necessary for a better understanding of the interaction of these reflexes producing integrated physiological responses in daily life situations or in pathological states.

A recent report showed that the cardiodecelerating capacity of the carotid baroreflex remains active during exercise in man, and may even be sensitized by the chemoreflexinduced increase in arterial pressure, but is not affected by cardiopulmonary baroreceptor activity (87), illustrating the diversity of interaction among these reflexes under those testing conditions.

We have studied the interplay among these reflexes using the experimental model of hypertension induced by inhibition of nitric oxide synthase using L-NAME. This hypertension is largely mediated by sympathetic activity to the heart and resistance vessels $(8,88)$. An important finding in this model was the observation that the cardiac vagal tone was almost abolished in L-NAMEtreated rats (8). We speculate that this autonomic disturbance, especially the decreased cardiac vagal activity, could result in upregulation and consequently could enhance the vagal activity for any triggered neural reflex using this common pathway to the heart. First of all, using bolus injections of the vasopressor phenylephrine and the vasodepressor sodium nitroprusside we tested 
the arterial baroreceptor sensitivity by the sigmoidal curve-fitting equation and observed an exaggerated baroreflex gain (Figure 1 , middle panel) mainly due to vagal reflex bradycardia (9). Thus, we postulated that the activation of neural reflexes originating in other cardiovascular sensory systems and related to other specific cardiovascular functions would result in a similar cardiac response. In fact, testing the serotonin-5- $\mathrm{HT}_{3}$-sensitive cardiopulmonary receptors to evoke the Bezold-Jarisch reflex we observed an exaggerated bradycardia and hypotension in L-NAME-treated rats (51). In addition, we also tested the chemoreflex and, as expected, the L-NAME-treated rats showed an enhanced $\mathrm{KCN}$-induced bradycardia (Figure 8). At least two hypotheses could explain this potentiated bradycardia: a) a possible dysfunction at central sites involved in the neural baroreflex, the BezoldJarisch reflex and/or the chemoreflex pathways, or b) possible changes directly in the heart. Thus, we tested the reactivity of cardiac muscarinic receptors to acetylcholine in isolated perfused hearts using the Langendorff technique and observed a profound

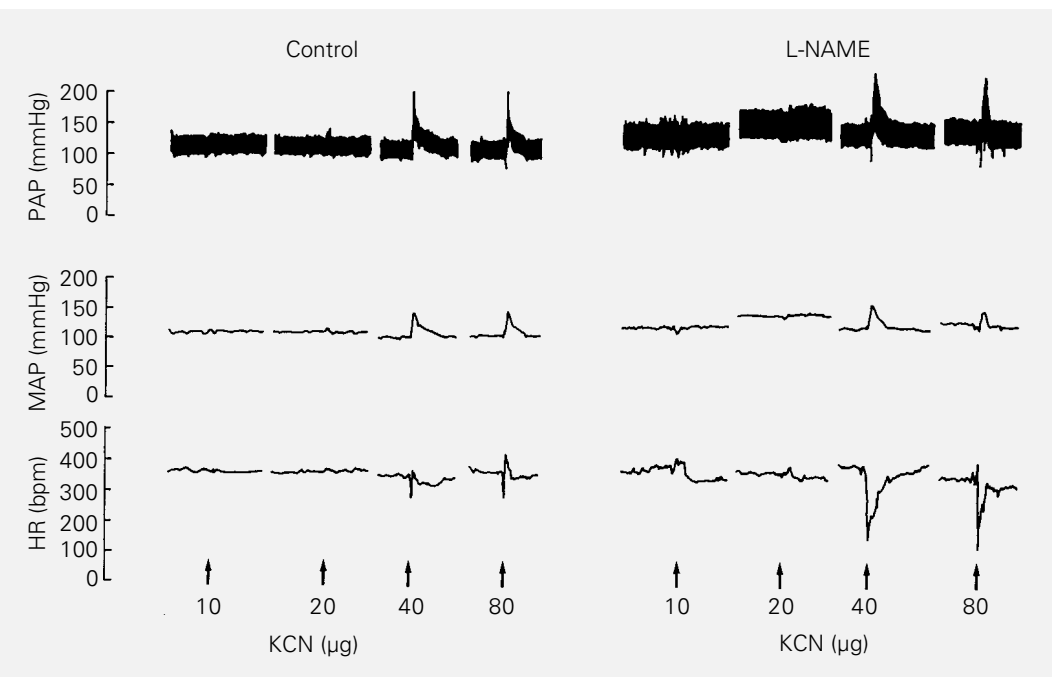

Figure 8 - Typical recording showing the $\mathrm{KCN}$-induced chemoreflex comparing the changes in pulsatile (PAP) and mean (MAP) arterial pressure and heart rate (HR) in a rat treated with $\mathrm{N}$-nitro-L-arginine methyl ester (L-NAME, $0.5 \mathrm{mg} / \mathrm{ml}$ added to the drinking water for 3 days) with a control rat.

enhancement in L-NAME-treated rats compared to control rats (7). This series of experiments supports the hypothesis of an important functional interplay among the arterial baroreceptor reflex, the cardiopulmonary Bezold-Jarisch reflex and the chemoreceptor reflex in pathophysiological conditions.

\section{References}

1. Chalmers JP, Kapoor V, Llewellyn-Smith IJ, Minson JB \& Pilowsky PM (1992). Central control of blood pressure. European Heart Journal, 13 (Suppl A): 2-9.

2. Cowley Jr AW (1992). Long-term control of arterial blood pressure. Physiological Reviews, 72: 231-300.

3. Marshall JM (1994). Peripheral chemoreceptors and cardiovascular regulation. Physiological Reviews, 74: 543-593.

4. Sleight $P$ (1991). Role of the baroreceptor reflexes in circulatory control, with particular reference to hypertension. Hypertension, 18 (Suppl III): 31-34.

5. Spyer KM (1990). The central nervous organization of reflex circulatory control. In: Loewy AD \& Spyer KM (Editors), Central Regulation of Autonomic Functions. Oxford University Press, Oxford, 168-188.
6. Vasquez EC (1994). Contribution of the cardiopulmonary reflex to the cardiovascular regulation in normal and pathophysiological states. Brazilian Journal of Medical and Biological Research, 27: 10491064

7. Araujo MT, Barker LA, Cabral AM \& Vasquez EC (1996). Inhibition of nitric oxide synthase causes profound enhancement of the Bezold-Jarisch reflex. Hypertension, 28: 513 (Abstract).

8. Cunha RS, Cabral AM \& Vasquez EC (1993). Evidence that the autonomic nervous system plays a major role in the LNAME-induced hypertension in conscious rats. American Journal of Hypertension, 6: 806-809.
9. Vasquez EC, Cunha RS \& Cabral AM (1994). Baroreceptor reflex function in rats submitted to chronic inhibition of nitric oxide synthesis. Brazilian Journal of Medical and Biological Research, 27: 767-774.

10. Guyenet PG (1990). Role of the ventral medulla oblongata in blood pressure regulation. In: Loewy AD \& Spyer KM (Editors), Central Regulation of Autonomic Function. Oxford University Press, Oxford, 145-167.

11. Loewy AD \& Spyer KM (1990). Vagal preganglionic neurons. In: Loewy $A D$ \& Spyer KM (Editors), Central Regulation of Autonomic Function. Oxford University Press, Oxford, 68-87. 
12. Varner KJ, Vasquez EC, Lewis SJ \& Brody MJ (1991). Lesions of neurons in rostral ventrolateral medulla (RVLM) alter cardiopulmonary reflex in spontaneously hypertensive rats (SHR). Neuroscience Abstracts, 17: 994.

13. Schenberg LC, Brandao CAL \& Vasquez EC (1995). Role of periaqueductal gray matter in hypertension in spontaneously hypertensive rats. Hypertension, 26 (Suppl II): 125-128.

14. Chapleau MW, Cunningham JT, Sullivan MJ, Wachtel RE \& Abboud FM (1995). Structural versus functional modulation of the arterial baroreflex. Hypertension, 26: 341-347.

15. Li Z, Su X \& Chapleau MW (1995). Role of cyclooxygenase metabolites in mediating platelet-induced baroreceptor dysfunction. American Journal of Physiology, 269 (Heart and Circulation Physiology, 38): H599-H608.

16. Matsuda T, Bates JN, Lewis SJ, Abboud FM \& Chapleau MW (1995). Modulation of baroreceptor activity by nitric oxide and S-nitrosocysteine. Circulation Research, 76: 426-433.

17. Ferrari AU, Daffonchio A, Sala C, Gerosa S \& Mancia G (1980). Atrial natriuretic factor and arterial baroreceptor reflexes in unanesthetized rats. Hypertension, 15: 162167.

18. Chapleau MW, Hajduczok G \& Abboud FM (1988). Mechanisms of resetting of arterial baroreceptors: An overview. American Journal of Medical Sciences, 295: 327-334.

19. Head GA (1994). Cardiac baroreflexes and hypertension. Clinical and Experimental Pharmacology and Physiology, 21: 791802.

20. Korner PI (1989). Baroreceptors in hypertension. Clinical and Experimental Pharmacology and Physiology, 15: 45-64.

21. Zanchetti A \& Mancia G (1991). Cardiovascular reflexes and hypertension. Hypertension, 18 (Suppl III): 13-21.

22. Andresen MC, Krauhs JM \& Brown AM (1978). Relationship of aortic wall and baroreceptor properties during development in normotensive and spontaneously hypertensive rats. Circulation Research, 43: 728-738

23. Gordon FJ, Matsuguchi H \& Mark AL (1981). Abnormal baroreflex control of heart rate in prehypertensive and hypertensive Dahl genetically salt-sensitive rats. Hypertension, 3 (Suppl I): 135-141.
24. Moyses MR, Cabral AM, Bissoli N \& Vasquez EC (1994). Time course of changes in sigmoidal-fitting baroreceptor curves in one-kidney, one clip hypertensive rats. Hypertension, 23 (Suppl I): 8792.

25. Moyses MR, Cabral AM, Marcal D \& Vasquez EC (1994). Sigmoidal fitting barocurve analysis in renovascular 2K1C hypertensive rats. Brazilian Journal of Medical and Biological Research, 27: 1419-1424.

26. Head GA \& Adams MA (1988). Time course of changes in baroreceptor reflex control of heart rate in conscious SHR and WKY: contribution of the cardiac vagus and sympathetic nerves. Clinical and Experimental Pharmacology and Physiology, 15: 289-292.

27. Minami N \& Head GA (1993). Relationship between cardiovascular hypertrophy and cardiac baroreflex function in spontaneously hypertensive and stroke-prone rats. Journal of Hypertension, 11: 523-533.

28. Liu J-L, Murakami H \& Zucker IH (1996). Effects of NO on baroreflex control of heart rate and renal nerve activity in conscious rabbits. American Journal of Physiology, 270 (Regulatory, Integrative and Comparative Physiology, 39): R1361R1370.

29. Scrogin KE, Veelken R \& Luft FC (1994). Sympathetic baroreceptor responses after chronic N-nitro-L-arginine methyl ester treatment in conscious rats. Hypertension, 23 (Suppl 2): 982-986.

30. Meyrelles SS, Mill JG, Cabral AM \& Vasquez EC (1996). Cardiac baroreflex properties in myocardial infarcted rats. Journal of the Autonomic Nervous System, 60: 163-168.

31. Higuchi S, Morgan DA \& Mark AL (1988). Contrasting reflex effects of chemosensitive and mechanosensitive vagal afferents. Hypertension, 11: 674-679.

32. Thoren P (1979). Role of cardiac vagal Cfibers in cardiovascular control. Review of Physiology, Biochemistry and Pharmacology, 86: 1-94.

33. Ustinova EE \& Schultz HD (1994). Activation of cardiac vagal afferents in ischemia and reperfusion: Prostaglandins versus oxygen-derived free radicals. Circulation Research, 74: 904-911.

34. Felder RB \& Mifflin SW (1994). Baroreceptor and chemoreceptor afferent processing in the solitary tract nucleus. In: Barraco IRA (Editor), Nucleus of the Solitary Tract. CRC Press, London, 169-186.
35. Varner KJ, Vasquez EC, Lewis SJ \& Brody MJ (1990). Cardiovascular reflex effects of chronic lesions of rostral ventrolateral (RVLM) and rostral ventromedial (RVMM) medulla in rats. FASEB Journal, 4: 557A.

36. Varner KJ, Vasquez EC, Lewis SJ, Machado BH, Grosskreutz CL, Simon JS \& Brody MJ (1991). Regulation of autonomic cardiovascular function by the rostral ventromedial medulla. In: Kunos G \& Ciriello J (Editors), Central Neural Mechanisms in Cardiovascular Regulation. Birkhäuser, Boston, 29-36.

37. Varner KJ, Vasquez EC \& Brody MJ (1994). Excitotoxin-induced lesions of rostral ventromedial or rostral ventrolateral medulla prevent neurogenic hypertension. Hypertension, 24: 91-96.

38. Vasquez EC, Lewis SJ, Varner KJ \& Brody MJ (1991). Lesions of rostral ventrolateral (RVLM) but not rostral ventromedial medulla (RVMM) attenuate 5-HT-induced reflex tachycardia. FASEB Journal, 5: 743A.

39. Saito K, Yoshioka M, Kohya T \& Kitabatake A (1994). Involvement of muscarinic M1 receptor in the central pathway of the serotonin-induced Bezold-Jarisch reflex in rats. Journal of the Autonomic Nervous System, 49: 61-68.

40. Bogle RG, Pires JGP \& Ramage AG (1990). Evidence that central 5-HT1A receptors play a role in the von BezoldJarisch reflex in the rat. British Journal of Pharmacology, 100: 757-760.

41. Mark AL (1983). The Bezold-Jarisch reflex revisited: Clinical implications of inhibitory reflexes originating in the heart. Journal of the American College of Cardiology, 1: 90-102.

42. Meyrelles SS, Cabral AM \& Vasquez EC (1994). Impairment of the Bezold-Jarisch reflex in conscious rats with myocardial hypertrophy. Brazilian Journal of Medical and Biological Research, 27: 1065-1069.

43. Perez-Gomez F \& Garcia-Aguado A (1977). Origin of ventricular reflexes caused by coronary arteriography. British Heart Journal, 39: 967-973.

44. Chianca Jr DA \& Machado BH (1994). The sensitivity of the Bezold-Jarisch reflex is increased in rats with sinoaortic deafferentation. Brazilian Journal of Medical and Biological Research, 27: 775-781.

45. Mark AL \& Kerber RE (1982). Augmentation of cardiopulmonary baroreflex control of forearm vascular resistance in borderline hypertension. Hypertension, 4: 3946. 
46. Meyrelles SS, Bernardes C, Modulo R, Mill JG \& Vasquez EC (1996). BezoldJarisch reflex in myocardial infarcted rats. Journal of the Autonomic Nervous System (in press).

47. Verberne AJM, Young NA \& Louis WJ (1988). Impairment of inhibitory cardiopulmonary vagal reflexes in spontaneously hypertensive rats. Journal of the Autonomic Nervous System, 23: 63-68.

48. Thames MD \& Johnson LN (1985). Impaired cardiopulmonary baroreflex control of renal nerves in renal hypertension. Circulation Research, 57: 741-747.

49. Ferrari AU, Gordon FJ \& Mark AL (1984). Impairment of cardiopulmonary baroreflexes in Dahl salt-sensitive rats fed low salt. American Journal of Physiology, 247 (Heart and Circulation Physiology, 16): $\mathrm{H} 119-\mathrm{H} 123$.

50. Victor RG, Morgan DA, Thoren P \& Mark AL (1986). High salt diet sensitizes cardiopulmonary baroreflexes in Dahl salt-resistant rats. Hypertension, 8 (Suppl II): 21-27.

51. Araujo MT, Cabral AM \& Vasquez EC (1995). Exaggerated Bezold-Jarisch reflex in the hypertension induced by inhibition of nitric oxide synthesis. Brazilian Journal of Medical and Biological Research, 28: 1009-1012.

52. Marshall JM (1987). Analysis of cardiovascular responses evoked following changes in peripheral chemoreceptor activity in the rat. Journal of Physiology, 394: 393-414.

53. Finley JCW \& Katz DM (1992). The central organization of carotid body afferent projections to the brainstem of the rat. Brain Research, 572: 108-116.

54. McAllen RM (1992). Actions of carotid chemoreceptors on subretrofacial bulbospinal neurons in the cat. Journal of the Autonomic Nervous System, 40: 181-188.

55. Koshiya N, Huangfu D \& Guyenet PG (1993). Ventrolateral medulla and sympathetic chemoreflex in the rat. Brain Research, 609: 174-184.

56. Vardhan A, Kachroo A \& Sapru HN (1993). Excitatory amino acid receptors in commissural nucleus of the NTS mediate carotid chemoreceptor responses. American Journal of Physiology, 264 (Regulatory, Integrative and Comparative Physiology, 34): R41-R50.

57. Amano M, Sari T \& Kubo T (1994). Excitatory amino acid receptors in the rostral ventrolateral medulla mediate hypertension induced by carotid body chemoreceptor stimulation. Naunyn-Schmiedeberg's Archives of Pharmacology, 349: 549-554.
58. Chitravanshi VC, Kachroo A \& Sapru HN (1994). A midline area in the nucleus commissuralis of NTS mediates the phrenic nerve responses to carotid chemoreceptor stimulation. Brain Research, 662: 127-133.

59. Hayward LF \& Felder RB (1995). Peripheral chemoreceptor inputs to the parabrachial nucleus of the rat. American Journal of Physiology, 268 (Regulatory, Integrative and Comparative Physiology, 37): R707-R714.

60. Zhang W \& Steven WM (1995). Excitatory amino-acid receptors contribute to carotid sinus and vagus nerve evoked excitation of neurons in the nucleus of the tractus solitarius. Journal of the Autonomic Nervous System, 55: 50-56.

61. Sun M-K \& Spyer KM (1991). Responses of rostroventrolateral medulla spinal vasomotor neurons to chemoreceptor stimulation in rats. Journal of the Autonomic Nervous System, 33: 79-84.

62. Sapru HN \& Krieger AJ (1977). Carotid and aortic chemoreceptor function in the rat. Journal of Applied Physiology, 42: 344-348.

63. Gonzáles C, Almaraz L, Obeso A \& Rigual $R$ (1992). Oxygen and acid chemoreception in the carotid body chemoreceptors. Trends in Neurosciences, 15: 1146-1153.

64. Housley GD, Martin-Body RL, Dawson NJ \& Sinclair JD (1987). Brain stem projections of the glossopharyngeal nerve and its carotid sinus branch in the rat. Neuroscience, 22: 237-250.

65. Ciriello J, Hrycyshyn AW \& Calaresu FR (1981). Horseradish peroxidase study of brain stem projections of carotid sinus and aortic depressor nerves in the cat. Journal of the Autonomic Nervous System, 4: 43-61.

66. Donoghue S, Felder RB, Jordan D \& Spyer KM (1984). The central projections of carotid baroreceptors and chemoreceptors in the cat: a neurophysiological study. Journal of Physiology, 347: 397-409.

67. Chitravanshi VC \& Sapru HN (1995). Chemoreceptor sensitive neurons in commissural subnucleus of nucleus tract solitarius of the rat. American Journal of Physiology, 268 (Regulatory, Integrative and Comparative Physiology, 37): R851R858.

68. Housley GD \& Sinclair JD (1988). Localization by kainic acid lesions of neurones transmitting the carotid chemoreceptor stimulus for respiration in rat. Journal of Physiology, 406: 99-114.
69. Haibara AS, Colombari E, Chianca Jr DA Bonagamba LGH \& Machado BH (1995). NMDA receptors in NTS are involved in bradycardic but not in pressor response of chemoreflex. American Journal of Physiology, 269 (Heart and Circulation Physiology, 38): $\mathrm{H} 1421-\mathrm{H} 1427$.

70. Mifflin SW (1992). Arterial chemoreceptor input to nucleus tractus solitarius. American Journal of Physiology, 263 (Regulatory, Integrative and Comparative Physiology, 33): R368-R375.

71. Franchini KG \& Krieger EM (1992). Carotid chemoreceptors influence arterial pressure in intact and aortic denervated rats. American Journal of Physiology, 262263 (Regulatory, Integrative and Comparative Physiology, 34): R677-R683.

72. Biscoe TJ \& Duchen MR (1990). Monitoring $\mathrm{PO}_{2}$ by the carotid chemoreceptor. News in Physiological Sciences, 5: 229237.

73. Franchini KG \& Krieger EM (1993). Cardiovascular responses of conscious rats to carotid body chemoreceptor stimulation by intravenous KCN. Journal of the Autonomic Nervous System, 42: 63-70.

74. Habeck J-O (1991). Peripheral arterial chemoreceptors and hypertension. Journal of the Autonomic Nervous System, 34: 1-8.

75. Trzebski A (1992). Arterial chemoreceptor reflex and hypertension. Hypertension, 19: 562-566.

76. Habeck J-O, Honig A, Pfeiffer C \& Schmidt M (1981). The carotid bodies in spontaneously hypertensive (SHR) and normotensive rats - a study concerning size, location and blood supply. Anatomischer Anzeiger, 150: 374-384.

77. Smith $P$, Jago R \& Heath D (1984). Glomic cells and blood vessels in the hyperplastic carotid bodies of spontaneously hypertensive rats. Cardiovascular Research, 18: 471-482.

78. Pallot DJ (1987). The mammalian carotid body. Advances in Anatomy, Embryology and Cell Biology, 102: 1-90.

79. Edwards C, Heath D \& Harris P (1971) The carotid body in emphysema and left ventricular hypertrophy. Journal of Pathology, 104: 1-13.

80. Fukuda Y, Sato A \& Trzebski A (1987). Carotid chemoreceptor discharge responses to hypoxia and hypercapnia in normotensive and spontaneously hypertensive rats. Journal of the Autonomic Nervous System, 19: 1-11. 
81. Trzebski A, Malgorzata T, Zoltowski M \& Przybylski J (1982). Increased sensitivity of the arterial chemoreceptor drive in young men with mild hypertension. Cardiovascular Research, 16: 163-172.

82. Chen IH (1979). Interaction between the baroreceptor and Bezold-Jarisch reflexes. American Journal of Physiology, 237 (Heart and Circulation Physiology, 3): $\mathrm{H} 655-\mathrm{H} 661$.

83. Daly MB (1985). Interactions between respiration and circulation. In: Cherniack NS \& Widdicombe JG (Editors), Handbook of Physiology. The Respiratory System II. American Physiological Society, Bethesda, MD, 526-594.
84. Brunner MJ, Wallace A \& MacAnespie CL (1988). Interaction of carotid chemoreceptor and baroreceptor reflexes in anesthetized dogs. American Journal of Physiology, 254 (Regulatory, Integrative and Comparative Physiology, 23): R1-R10.

85. Mifflin SW (1993). Inhibition of chemoreceptor inputs to nucleus of tractus solitarius neurons during baroreceptor stimulation. American Journal of Physiology, 265 (Regulatory, Integrative and Comparative Physiology, 34): R14-R20.

86. Marshall JM (1981). Interaction between the responses to stimulation of peripheral chemoreceptors and baroreceptors: the importance of chemoreceptor activation of the defence areas. Journal of the Autonomic Nervous System, 3: 389-400.
87. Eiken O, Convertino VA, Doerr DF, Dudley GA, Morariu G \& Mekjavic IB (1991). Interaction of the carotid baroreflex, the muscle chemoreflex and the cardiopulmonary baroreflex in man during exercise. Physiologist, 34 (Suppl 1): S118-S120.

88. Sander M, Hansen PG and Victor RG (1995). Sympathetically mediated hypertension caused by chronic inhibition of nitric oxide. Hypertension, 26: 691-695. 